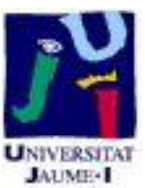

Título artículo / Títol article: The effect of meditation based on self-observation on cognitive responses in conflictive social interaction

Autores / Autors

Pinazo Calatayud, Daniel; Vazquez, Carolina

Revista:

Nordic Psychology

Versión / Versió:

Pre-print

Cita bibliográfica / Cita

PINAZO, Daniel; VAZQUEZ, Carolina. The effect bibliogràfica (ISO 690): of meditation based on self-observation on cognitive responses in conflictive social interaction. Nordic Psychology, 2014, vol. 66, no 3, p. 202-215.

url Repositori UJI:

http://hdl.handle.net/10234/128765 


\title{
The effect of meditation based on self-observation on cognitive responses in conflictive social interaction
}

Running Head: meditation, mindfulness and cognitive responses

\begin{abstract}
:
Conflictive social interactions are associated with the attribution of responsibility for our negative experiences to the other, and with a distant social perception of the other. When we meditate we acquire skills related to thought that allow us to observe how we perceive and signify interaction with the other, which distances us from the response to the meaning of this perception. This way of attending to events can have a negative effect on the tendency to make dispositional attributions, which are generally more conflictive, since the person making the attribution blames the other for the unpleasant situation he or she is experiencing. For this reason, the associated practice of meditation may affect social interactions by reducing conflict. The relationship between infrequent meditation, associated to the development of self-observation, with the locus of attribution for an unpleasant event, the perception of anger with oneself, and the social distance from the outgroup was analysed using a sample of 229 individuals (118 non-meditators and 111 unspecific meditators). Results show that meditation has the effect of reducing dispositional attributions, perception of anger, and social distance, and provide evidence for the moderating effect of self-observation ability.
\end{abstract}

Key words: Meditation, self-observation, attribution, social interaction and conflict. 


\section{Introduction}

The practice of mindfulness meditation can have numerous effects on the way people process information and react emotionally in their social interactions. Meditation mindfulness requires both the ability to anchor one's attention on what is occurring, and the ability to intentionally switch attention from one aspect of the experience to another (Keng, S.L.; Smoski, M.J. \& Robins, C.J., 2011). Mindfulness meditators learn to observe thoughts, to avoid immediate responses to impulses arising from experiences, to distance themselves from their perception of themselves and of the other, or to experience interactions without judgement. In sum, the mindfulness meditator develops a capacity to create distance between the observation of what he or she experiences and the response to the experience (Kabat-Zinn, 1990; Brown \& Ryan, 2003; Brown, Ryan \& Creswell, 2007; Williams, 2010). Meditation can develop the individual's ability to interact with his or her environment, by bringing him or her closer to the experience with a fundamental attitude of respect and acceptance, generating more understanding responses to what is happening at that moment. The ability to self-observe the internal processes that generate these responses might moderate the effect of meditation on interaction responses. Three responses associated to social interaction may be particularly sensitive to meditation and self-observation: 1) attribution of responsibility for harm to a third party; 2) the subjective perception of anger in a conflictive situation, and 3) the psychological distance from members of the outgroup.

Mindfulness is an efficient way to attain well-being and personal health benefits, as various training programmes have shown (e.g., Broderick, 2005; Brown \& Ryan, 2003; Shapiro, Brown \& Biegel, 2007). Mindfulness can be defined as an attentional state of mind by which cognitive processes interact with emotional processes to receive, perceive and manage information. It is a psychological state characterized by an open mind to present events. KabatZinn (1994: 4) described it as "paying attention on purpose, in the present moment, and 
nonjudgmentally to the unfolding of experience moment by moment". Two aspects stand out: 1 . The state of mindfulness is characterized by an awareness of the internal and external sensory and cognitive experience of the present moment. 2. This awareness leads to simply acknowledge and examine, without any judgment, elaboration, or emotional reaction to whatever arises. It includes elements of attention-regulation mechanisms and orientation to experience characterized by openness, acceptance, and nonjudgmentalism (Bishop, 2002; Bishop, et al. 2004; Brown \& Ryan, 2004; Hayes \& Shenk, 2004). Mindfulness is not a passive ability as it is an active cognitive ability in which conscious attention to the present moment allows the observer to retain and capture the object being observed without the filters of memory or expectation (Dreyfus, 2011). This capacity to be mindful, paying attention to the present moment may be a disposition or a temporal condition (Baer, Smith, Hopkins, Krietemeyer \& Toney, 2006). Regardless of the degree of dispositional features, the tool that has proven to be most effective for the development of mindfulness is meditation, a practice extended in the West in recent years without adherence to religious beliefs (Duerr, 2004; Hart, 2007; Kabat-Zinn, 1996). Since meditation is a mind-calming tool that ultimately results in mindfulness both terms tend to be merged in one concept; it must be highlighted, however, that mindful dispositions do not require the practice of meditation to be activated although they can be deepened by this practice.

The present study investigates social interaction responses as a function of meditation. One way in which meditation may affect social interaction responses is in the effect it has on the interpretation of perceived situations. Although there are variations in meditation techniques (Lutz, Slagter, Dunne \& Davidson, 2008) and their effects (Erisman \& Roemer, 2010), all types of meditation monitor and regulate internal cognitive processes. Meditation could therefore intervene in our interpretation of interactions with others, through a more compassionate internal perception of the experience, thus reducing conflict in the social interaction. Some studies find evidence that meditation enhances a compassionate perception of interaction with the other (e.g. 
Lutz, Greischar, Rawling, Ricard \& Davidson, 2004; Siegel, 2007) and encourages attitudes of proximity to the other (e.g. Segal, Williams \& Teasdale, 2002).

The development of self-observation appears to derive from the practice of meditation and should therefore have a clear association with it. Baer Smith, Hopkins, Krietemeyer and Toney (2006) point out that self-observation is particularly sensitive to the effect of meditation. Self-observation is one of the main factors of mindfulness (Baer et al., 2006). Nowadays the concepts of meditation and mindfulness tend to be used somewhat interchangeably. However, there are differences; roughly explained, meditation is sustaining focus on a very simple stimulus (such as breath) and mindfulness is observing the flow of all simple stimuli without thoughts or worry (Smith, 2005). The state of mindfulness allows for observing mental responses to the present moment. The mindfulness-meditation technique consists of allowing sensations and thoughts to arise, paying attention what happens in the present without censure. Self-observation is therefore a way of meditating and also a result of meditation. Training in self-observation enables the person to focus the attention of the experiences on internal processes, thus strengthening the effect of meditation on social interaction responses.

The regulation of internal processes can affect interaction responses. One expression of this association can be seen in the way we explain events. Attribution theory states that when we try to understand a situation, particularly when it is painful or frustrating, the first thing we do is to make a judgement (Heider, 1958; Weiner, 1985). However, we do not usually consider the judgement to be anything different from fact. Thus, when we attribute responsibility for our suffering to others, it becomes more of a fact in that we do not see how this has occurred. This type of attribution is potentially more aggressive, since it can cause greater harm and pain (Leary et al., 1998; Vangelisti \& Young, 2000; Young, 2004). When attribution is more generally made to the situation, 
the cause of the threat is less defined, which obliges us to observe more closely what is happening and the response we should make.

The appropriate response, such as anger, arises more easily in people with dispositional attributions. When the cause of a frustrating situation is attributed to an actor, anger towards that actor tends to increase more than when the cause of the frustration is attributed to the situation (Weiner, 1993, 1995). Hence, judging situations as dispositional is frequently accompanied by negative emotional reactions that intensify the conflict in the interaction. When meditation leads to the absence of reactivity, the person is becoming less conflictive (Langer, 1983, 1997).

Conflictive social interactions require that responsibility for our negative experiences be attributed to the other, together with a distanced social perception of the other. When we meditate we can develop a basic attitude of respect and acceptance of all individuals, subsumed within a positive frame of mind, that does not involve rejection (e.g. Dreyfuss, 2011; Garland, Gaylord \& Park,, 2009; Hill \& Updegraff, 2012; KabatZinn, 1990; Ochsner, Bunge, Gross \& Gabrieli, 2006). Distance from the other is lessened if we do not judge and if we attend to who the other is from our internal state. Similarly, the development of self-observation, of realising how we tend to reject the other, could bring others closer to ourselves. Two important studies in the field of cooperation, Hoffman, McCabe, Shachat \& Smith (1994) and Hoffman, McCabe, \& Smith (1996), have shown how perceived social distance increases with selfish attitudes and anonymity. Furthermore, social distance is related to the image one has of oneself. According to Sheriff and Sheriff (1975), the members of a group that perceives itself as dominant in a relationship will maintain a greater social distance from outgroups, which are perceived as inferior. Meditation can help people to discriminate between these 
mental representations and the external event, and increase the acceptance of the image they have of their own experience, without pre-judgements.

The aim of this paper is to study the relationship meditation has in socio-cognitive responses of responsibility attribution, the subjective perception of anger and the perception of social distance from the outgroup. The study also analyses the moderating role of self-observation in these responses. These aims lead us to the following hypotheses:

Hypothesis 1. People who have meditated for more than 140 hours and fewer than 500 hours, have a more situational than dispositional attributional style.

Hypothesis 2. People who have not meditated have a more dispositional than situational attributional style.

Hypothesis 3. People who have meditated have significantly higher self-observation scores, and lower scores in subjective perception of anger and social distance from the outgroup than those who have not meditated.

Hypothesis 4. Self-observation has a moderating effect on meditation. The effect of meditation on social interaction will be significantly more acute in people with high selfobservation scores.

\section{Method}

\section{Participants}

Of the 229 participants in this study, $37.6 \%$ were aged between 18 and 24 years, $36.2 \%$ between 25 and 35 years, and $25.8 \%$ were over the age of 35 . The total number of men was $59(25.8 \%)$ and women, $169(73.8 \%)$. Educational levels were divided as follows: primary (3.5\%), secondary (6.1\%) and university (90\%). Of the total, 111 (48.5\%) people had meditation experience and $118(51.5 \%)$ had never meditated.

\section{Procedure}


Meditators were selected through an announcement posted in the university, calling for people with some meditation experience to take part in research related to their state of mind. People who responded to the announcement then completed a short survey on their experience of meditation. Those selected a) responded that they meditated in some form, b) that they did so somewhat unsystematically, without following any specific discipline, and c) their total experience of meditation was more than 140 hours, but fewer than 500 hours. The number of hours was chosen arbitrarily, as it was considered to guarantee that those chosen were not experienced meditators.

Non-meditators were chosen at random by means of a survey at the university entrance. The survey opened with a question about meditation experience in order to identify people who had never meditated.

\section{Instruments}

The questionnaire consisted of three parts:

Meditation: 1. Irregular meditator, unspecific $(N=111)$ : participants were asked to estimate the total time they had spent meditating. Those selected reported having meditated for more than 140 hours and fewer than 500 hours. The mean estimated time spent meditating was 320.09 hours $(S D=225.71)$.

2. Non-meditator. Individuals who had never meditated $(N=118)$.

Self-observation: we used the 'observe' factor $(M=5.802, S D=1.651 ; \alpha=.863)$ from Baer et al.'s Five Facet Mindfulness Questionnaire (2006). These authors state that the five facets can be used independently of the general questionnaire. Respondents answered on a 9-point Likert-type scale $(1=$ never or very rarely true, $9=$ very often or always true).

Level of self-observation: The self-observation variable was dichotomised into high and low self-observation, taking the mean self-observation level of the study 
participants as a reference $(M=5.802)$. High self-observation participants were those with self-observation scores of 5.81 and above $(N=111 ; 48.5 \% ; M=7.165 ; S D .=.871)$, whereas low self-observation participants had scores from 1 to $5.8(N=118 ; 51.5 \% ; M=4.520$; $S D=1.086)$

Attributional style. Participants were asked to read the description of a situation in which an accident had occurred: "You leave the house in the morning with your son or daughter (or younger brother or sister) and you are late for school. You cross the street. A car knocks you over. You didn't see it, you didn't have time to react. It seemed to speed off, you didn't have time .... The child is lying on the floor bleeding." Faced with this situation, participants were asked to give an open response to the question 'What do you think happened?' Responses were divided into three categories: 1. External dispositional attribution, in which the observer directly blames the actor (e.g. 'the driver was a bit crazy. He must have had a bad night'; 'the person driving the car was drunk, had been taking drugs, or he had done something illegal, something that made him drive off'); 2. Situational attribution, in which the observer is unclear as to who was ultimately to blame for the accident (e.g. 'we were running late so we didn't see the car which was going too fast and ran us over'; 'we crossed the road in a hurry, practically without looking. The driver didn't see us, and we didn't see him either'; 'maybe he didn't see us, he must have been worried, I wasn't concentrating, I should have left home earlier, he got scared'); 3. Internal dispositional attribution, in which the observer considers that his or her actions are to blame for the accident ('I wasn't concentrating when I crossed the street and I didn't see the car coming towards us'; 'I was in a hurry and I acted rashly. We crossed without paying proper attention'). The authors classified the responses into one of the three categories independently of each other. After this initial phase, each analyst's solutions were paired up. The solutions that coincided were categorised directly, 
accounting for $60 \%$ of the responses. The total number of questionnaire respondents with external dispositional responses was $N=54$, with situational responses $N=175$, and with internal dispositional responses $N=12$. Given that the aim of the study was to compare external dispositional responses to the actor with situational responses, the internal dispositional responses were eliminated from the study. Hence, two categories remained in this variable: 1 . External dispositional attribution $(N=54) ; 2$. Situational attribution $(N=175)$.

Subjective perception of anger: a Likert-type scale ( $1=$ very angry) to ( $9=$ not at all angry) was used to measure the anger the person felt when faced with the situation described in the attributional style variable $(M=3.253 ; S D=2.418)$. Using the EFFQ Reactivity scale to validate the anger response with a reactive response to the dilemma, we performed a correlation between the two to analyze possible convergence in the response. We find a significant correlation between Reactivity and Anger in the overall sample $(r=.503 ; p<.001)$, in the meditador sample $(r=.514 ; p<.001)$, and in the nonmeditator sample ( $r=.392 ; p=.024)$. The single item subjective measure of anger is therefore shown to behave similarly to a reactive response in the area of conscious attention.

Social distance: we evaluated the perceived distance between the participant and a social group using the Bogardus social distance scale (1947). This scale, originally designed to measure the level of contact desired with members of other groups, considers willingness to accept the other at various levels of closeness to indicate social distance from social groups. According to Biernat and Crandall (1993), it is one of the most useful and simple instruments to measure prejudice against outgroups. The scale asked participants to evaluate their degree of acceptance of a person from a threatening group (a score of one indicated no social distance, with full acceptance of the person from the 
threatening group; a score of nine indicated the greatest social distance). The respondents explored their willingness to be close to the supposedly threatening person, using five items, each one representing a greater social closeness to the respondent. The Bogardus social distance scale is a cumulative scale, since the agreement with any item implies agreement with all preceding items. In this study we used five items of closeness, from greatest to least social distance. The first item on our scale read as follows: 'think of the type of person that you least identify with, whether from another ethnic group or religion or a person with other values. Would you be happy ...... (respond on a scale from 1 (NO) to 9 (YES)), 1. to have him/her as a visitor in your city?, 2. to have him/her as a neighbour in the same neighbourhood?, 3. to have him/her as a neighbour in the same building?, 4. to have him/her as a friend?, 5. to marry the person or have your son or daughter marry him/her?' A compound score of social distance was obtained by totalling the scores from each item from the scale of 1 (greatest social distance) to 9 (least social distance) and dividing the result by $5(M=4.083 ; S D=1.768)$.

\section{Results}

The aim of the study was to analyse the effect of irregular meditation on attributional style, anger response and social distance. We also analysed the role of selfobservation in meditation and its effect on these social interaction responses.

The results were obtained by first conducting a chi-square test for the meditation experience variable and the demographic variables, to uncover any bias in the age, sex or educational groups making up the sample. The $\chi^{2}$ test revealed no differences between educational level and meditation experience or otherwise $\left(\chi^{2}=4.110 ; p=.128, d f=2\right)$, nor in relation to gender $\left(\chi^{2}=2.806 ; p=.094 ; d f=2\right)$. However, differences were found in the age variable $\left(\chi^{2}=16.432 ; p<.001 ; d f=2\right)$. Empirical frequency of meditators and non- 
meditators according to age is reported in Table 1. Older people are more likely to meditate than younger people (Table 1).

\section{Insert table 1}

As a previous stage, we tested the relationship between attributive style, anger responses and social distance. We performed an ANOVA for respondents who had made dispositional attributions, and those who had made situational attributions, in relation to anger and social distance (Table 2). The results indicate that the situational attributional style is more significantly related to a lower anger response and less social distance.

\section{Insert table 2}

We then tested the research hypotheses by analysing the relationship of meditation experience with the dependent variables. First, the relation between meditation and attributional style was tested with a $\chi^{2}$ analysis $\left(\chi^{2}=4.99 ; p=.026 ; d f=1\right)$. The results indicated that the most frequent attributional response among the group of meditators was situational attribution (hypothesis 1). Among the non-meditators, the dispositional attributional style was more frequent than among the meditators (hypothesis 2) (Table 1).

Secondly, we performed ANOVAs to establish the effect that meditational experience or lack of experience has on anger response and social distance, and selfobservation (hypothesis 3) (Table 2). The results show that the meditational experience is associated with both higher self-observation scores and less intense subjective perception of anger, and less social distance from threatening others. 
Hypothesis 4, which predicted a moderating effect of self-observation on meditation, was tested in two stages. For each group (meditators and non-meditators) we first analysed the relationship between level of self-observation and attributional style, by performing a chi-square test. This analysis revealed no relationship between selfobservation and attributional style in the case of non-meditators $\left(\chi^{2}=.100 ; p=.752 ; d f=1\right)$; however, this relationship was significant in the case of the meditator group $\left(\chi^{2}=8.510\right.$; $p=.004 ; d f=1)$. The situational attributional style was more frequent among those with high self-observation scores, whereas in the group with lower self-observation scores the dispositional style was more frequent (Table 3).

\section{Insert table 3}

Secondly we performed an ANOVA for each group (meditators and nonmeditators) on subjective perception of anger and social distance. Our findings indicate that self-observation moderates the effects of meditation on social interaction. High selfobservation intensifies the reduction of social distance in the meditator group, but subjective perception of anger does not change among these participants. In contrast, high self-observation in the non-meditator group lowered scores for subjective perception of anger, but did not affect social distance results (Table 4).

\section{Insert Table 4}

\section{Discussion}

The aim of the present study was to explore the relationship between meditation and response to conflictive social situations, as well as the effect associated with self- 
observation ability. The results showed that both meditation and development of selfobservation are tools that can influence conflictive interactions by reducing levels of conflict.

Our results show that experience of meditation is associated with a higher frequency of situational attribution. Moreover, participants who made dispositional attributions demonstrated higher levels of anger and greater social distance. Meditation appears to regulate the internal processes of explaining the external experience, by reducing the conflictive potential in the response. The results appear to confirm a link between meditation and the activation of responses that involve lower intergroup aggression. Meditators tend to perceive reality less aggressively, which is reflected in the perception of their emotional response. They also registered lower levels of rejection towards members of the outgroup.

Meditation appears to have an even greater effect on certain aspects of interaction when it is associated with higher levels of self-observation. Specifically, the tendency of meditators to make situational attributions is moderated by their self-observation ability. Self-observation increases the frequency of the response as compared with nonmeditators, or meditators with low self-observation. In addition, self-observation intensifies the effect meditation has of reducing social distance. Both attributional style and social distance are cognitive responses. These results appear to support previous evidence indicating that meditation encourages a more compassionate view of the other, and fosters acceptance (e.g. Lutz, Greischar, Rawling, Ricard \& Davidson, 2004; Segal, Williams, Teasdale, 2002; Siegel ,2007).

In contrast, individuals who had not meditated, but had high self-observation scores, showed lower levels of anger than those with low scores. Self-observation improves the effect of reducing subjective perception of anger among non-meditators. 
This begs the question of why self-observation moderates the effect among nonmeditators in emotional responses, and among meditators in cognitive responses. Selfobservation is a facet of full attention, and in people who have not learned to develop the set of full attention skills through meditation, self-observation may have the effect of reducing impulsivity. Therefore, self-observation would not have an additional effect on the emotional response among people with meditation experience. Based on this hypothesis, self-observation ability is not enough on its own to affect the cognitive processes involved in social interaction, although it does so when it interacts with meditation. In other words, perhaps the effect of self-observation on cognitive processes as a causal explanation of a more dispositional style and lower social distance, as observed in the meditator group, may be due to the fact that self-observation acts in individuals who have learned to reduce their negative emotional responses. Given that self-observation is a cognitive skill in recognising internal processes, it might be the case that it has a positive effect on anger in non-meditators, because they are not trained to contain their emotional responses. The size of the effect is small in attributional style (.013-.029), as is the effect of meditation experience (.021-.097). Again the size of the effect is small (.010-.075), as is the effect of meditation experience (.021-.097). Such small effects both from table 2 and the 4 , indicate little practical relevance of the results. However, considering the relative novelty of the study area, suggest the need to further explore theoretical these variables overcoming the limitations of this study. Further indepth research is required to explore whether meditation can bring members of different social groups closer together at a cognitive level, enabling greater mutual acceptance in itself, or through the development of self-observation or the reduction of emotional reactions. 
The findings from this study allow us to suggest that social relations can be improved through meditation. It is not an isolated effect; mindfulness has been shown to help in facing strong emotional states and in resolving interpersonal conflicts (HortonDeutsch \& Horton, 2003), as well as increasing empathy (Dekeyser, Raes, Leijsen, Leysen\&Dewulff, 2008). Peters et al. (2011) demonstrate that self-consciousness encourages more regulated behaviour, with fewer negative effects. Siegel (2007) suggests that there are neural systems which support experiences of synchronisation and resonance with other people. These systems become self-reflexive with the practice of mindfulness, developing empathy, understanding and love for ourselves and our experience (Siegel, 2007).

In summary, responses that could derive in more aggressive interactions from individuals with more meditation experience were affected in such a way that the aggression of the experience was lower. It should be noted that these differences were observed a group of people with a limited and unsystematic experience of meditation. The results presented in this study suggest that meditation has the potential to facilitate less aggressive and conflictive social interactions. These effects can be moderated by the development of self-observation. Future research, as noted by Langer (1997), could further explore the idea that meditation and/or the development of mindfulness skills might reduce the automatic responses associated with conflictive social interactions.

\section{Study limitations and future research lines}

Like all studies, this one has limitations. The limitations of this study are essentially related to the sample. Future research might usefully study experienced meditators in order to evaluate the possible effect of meditation experience on the various attribution responses. Future studies could also include more explanatory variables for the concept of mindfulness. This would extend understanding and more accurately test the 
extent to which the construct that delimits the concept of mindfulness affects the response of anger and social distance according to attributional style. The correlational nature of the study is also a limitation. Future studies might contribute more precise information by exploring the meditation experience with behavioural or physiological variables of mindfulness.

One of the most comprehensive measures of mindfulness is the Five Facet Mindfulness Questionnaire (FFMQ) with five factors-Observing, Describing, Acting with awareness, Non-judging, and Non-reactivity. Hierarchical confirmatory factor analyses, however, have suggested that only four of the FFMQ factors (i.e. all except Observing) were components of an overall mindfulness construct. However, studies that compare meditators and non-meditators have shown that mindfulness is related to high levels of Observing (Lilja, Lundh, Josefsson, Falkenström, 2013). This manuscript presents data for only one facet of the Five Facet Mindfulness Questionnaire. The Observing facet has been shown to function differentially in meditators vs non-meditators (Baer et al., 2008). The scales authors suggest that this is likely due to different interpretations of the facet depending on meditation experience. The different way of interpreting the items indicates that meditators and non-meditators perceive the meaning of self-observation differently. This is probably because their internal experience of this facet is different, which affects the way in which what they observe is represented. The Observing facet can moderate the direct effect of meditator or non-meditator status on the cognitive responses of the study. This moderator aspect does not arise with the other facets, since their function is similar in both groups. The changes observed in the rest of the EEFQ questionnaire facets concern the intensity in the development of the skill, but there is no evidence that this affects the function of these facets on other relational or psychological aspects. Although this facet can be used independently, the absence of the 
Acting with Awareness facet is particularly relevant, especially given previous findings demonstrating the high correlation between the Acting with Awareness facet and disinhibited and aggressive behavior and the importance of self-awareness in the discussion. In studies that aim to explore the differences in the psychosocial behavior of meditators and non-meditators, the facets not considered here should be included.

The use of a single item for attributional style, without any previously established instruments for validation of this method, and single item measures for anger is questionable, especially when numerous well-validated, multi-item questionnaires for these constructs exist. In addition, the attributional style measure does not appear to be very accurate. The majority of participants in this study responded with situational attribution, which suggests that the measure was not powerful enough to detect the differences in attributional style. The use of more valid questionnaires should solve this issue.

\section{References}

Baer, R. A., Smith, G. T., Hopkins, J., Krietemeyer, J., \& Toney, L. (2006). Using selfreport assessment methods to explore facets of mindfulness. Assessment, 13, 2745. doi:10.1177/1073191105283504

Barnes, S., Brown, K.W., Krusemark, E., Campbell, W.K., Rogge, R.D. (2007). The role of mindfulness in romantic relationship satisfaction and responses to relationship stress. Journal of Marital and Family Therapy, 33(4), 482-500.

Biernat, M. y Crandall, C.S. (1993). Racial attitudes. In J.P. Robinson, P.R. Shaver and L.S. Wrightsman (eds.): Measures of political attitudes, 297-412. San Diego: Academic Press.

Bogardus, E.S. (1947). Changes in racial distances. International Journal of Opinion and Attitude Research, 1(4), 55-62. 
Borders, A., Earleywine, M., \& Jajodia, A. (2010). Could Mindfulness Decrease Anger, Hostility, and Aggression by Decreasing Rumination? Aggressive Behavior, 36, 28-44. doi: 10.1002/ab.20327

Broderick, P. C. (2005). Mindfulness and coping with dysphoric mood: Contrasts with rumination and distraction. Cognitive Therapy and Research, 29(5), 501-510. doi: $\underline{10.1007 / \mathrm{s} 10608-005-3888-0}$

Brown, K. W., \& Ryan, R. M. (2003). The benefits of being present: Mindfulness and its role in psychological well-being. Journal of Personality and Social Psychology, 84, 822- 848. doi:10.1037/0022-3514.84.4.822

Brown, K. W., Ryan, R. M., \& Creswell, J. D. (2007). Mindfulness:Theoretical foundations and evidence for its salutary effects. Psychological Inquiry, 18, 211237. doi:10.1080/10478400701598298

Dekeyser, M., Raes, F., Leijssen, M., Leysen, S., y Dewulf, D. (2008). Mindfulness skills and interpersonal behaviour. Personality and Individual Differences, 44, 1235 1245

Dreyfus, G. (2011). Is mindfulness present-centered and non-judgmental? A discussion of the cognitive dimensions of mindfulness. Contemporary Buddhism 12(1), 41-54

Erisman, S. M.\& Roemer, L. (2010). Emotion, 10(1), 72-82. doi: 10.1037/a0017162

Garland, E. , Gaylord, S., \& Park, J. (2009). The role of mindfulness in positive reappraisal. Journal of Science and Healing, 5(1), 37-44

Heider, F. (1958). The psychology of interpersonal relations. Nueva York: Wiley.

Heppner,W., Kernis, H., Lakey C., Campbell, W., Goldman, B., Davis, P., \& Cascio, E. (2008). Mindfulness as a means of reducing aggressive behavior: Dispositional and situational evidence. Aggression Behaviour, 34, 486-496.

Hill, C.L.M., \& Updegraff, J.A. (2012). Mindfulness and its relationship to emotional regulation. Emotion, 12(1), 81-90. 
Hoffman, E., McCabe, K. \& Smith, V. (1996). Social Distance and Other Regarding Behavior in Dictator Games. American Economic Review, 86(3), 653-60.

Hoffman, E., McCabe, K., Shachat, J. \& Smith, V. (1994). Preferences, Property Rights and Anonymity in Bargaining Games. Games and Economic Behavior, 7(3), 34680.

Horton-Deutsch, S.L., y Horton, J.M. (2003). Mindfulness: Overcoming Intractable Confl ict. Archives of Psychiatric Nursing, XVII, 186-193.

Kabat-Zinn, J. (1990). Full catastrophe living: Using the wisdom of your body and mind to face stress, pain, and illness. New York, NY: Dell.

Kabat-Zinn, J. (2000). Indra's net atwork: The mainstreaming of Dharma practice in society. In G.Watson \& S. Batchelor (Eds.), The psychology of awakening: Buddhism, science, and our day-to-day lives (pp. 225-249). North Beach, ME: Weiser.

Keng, S.L.; Smoski, M.J. \& Robins, C.J., (2011). Effects of mindfulness on psychological health: A review of empirical studies. Clinical Psychology Review, 31, 1041-1056.

Langer, E. (1997). The power of mindful learning. Reading, MA: Addison-Wesley.

Langer, E. (1983). The psychology of control. Beverly Hills: Sage Publications

Leary, M. R., Springer, C., Negel, L., Ansell, E., \& Evans, K. (1998). The causes, phenomenology, and consequences of hurt feelings. Journal of Personality and Social Psychology, 74, 1225-1237.

Lilja, J.L., Lundh, L.-G., Josefsson, T. \&Falkenström, F. 2013. Observing as an essential facet of mindfulness: A comparison of FFMQ patterns in meditating and nonmeditating individuals. Mindfulness, 4, 203-212. 
Lutz, A., Greischar, L., Rawlings N., Ricard M. \& Davidson R. J. (2004). Long-term meditators self induce high-amplitude gamma synchrony during mental practice. PNAS, 101: 16369-16373.

Lutz, A., Slagter, H. A., Dunne, J. D., \& Davidson, R. J. (2008). Attention regulation and monitoring in meditation. Trends in Cognitive Sciences, 12, 163-169. doi:10.1016/j.tics.2008.01.005

Ochsner, K., Bunge, S.A., Gross, J.J., \& Gabrieli, J.D.E. (2006). Rethinking feelings: An fMRI study of the cognitive regulation of emotion. Journal of Cognitive Neuroscience, 14(8), 115-1229.

Peters, J.; Erisman, Sh.; Upton, B.; Baer, B. \& Roemer, L. (2011). A Preliminary Investigation of the Relationships Between Dispositional Mindfulness and Impulsivity. Mindfulness, 2, 228-235. doi: 10.1007/s12671-011-0065-2

Raffone, A., Tagini, A. \& Srinivasan, N. (2010). Mindfulness and the Cognitive Neuroscience of Attention and Awareness. Zygon 45 (3):627-646. doi: 10.1111/j.1467-9744.2010.01118.x

Segal, Z. V., Williams, J. M. G., \& Teasdale, J. D. (2002). Mindfulness-based cognitive therapy for depression: A new approach to preventing relapse. New York: Guilford Press.

Siegel, D. J. (2007). The Mindful Brain. Norton \& Company. New York. London.

Shapiro, S. L., Brown, K.W., \& Biegel, G. (2007). Teaching self-care to caregivers: The effects of Mindfulness-Based Stress Reduction on the mental health of therapists in training. Training and Education in Professional Psychology, 1, 105-115.

Sherif, M. \& Sherif, C. (1975). Psicología Social. Buenos Aires: Harla. 
Smith, J. C. (2005). Relaxation, meditation, \& mindfulness: A mental health practitioner's guide to new and traditional approaches. Springer Publishing Company.

Vangelisti, A. L., \& Young, S. L. (2000). When words hurt: The effects of perceived intentionality on interpersonal relationships. Journal of Social and Personal Relationships, 17, 393-424. doi: 10.1177/0265407500173005

Weiner, B. (1985). An attributional theory of motivation and emotions. Psychological Review, 92, 548-573.

Weiner, B. (1993). On sin versus sickness: A theory of perceived responsibility and social motivation. American Psychologist, 48, 957-965.

Weiner, B. (1995). Aggression. En B. Weiner (Ed.), Judgements of responsibility. A foundation for a theory of social conduct (pp. 186-215). Nueva York: Guilford Press.

Weinsteina, N., Brown, K., \& Ryan, R. (2009). A multi-method examination of the effects of mindfulness on stress attribution, coping, and emotional well-being. Journal of Research in Personality, 43, 374-385. doi:10.1016/j.jrp.2008.12.008

Williams, J. M. (2010). Mindfulness and Psychological Process. Emotion, 10(1), 1-7. doi: $10.1037 / \mathrm{a} 0018360$

Young, S. L. (2004). Factors that influence recipients' appraisals of hurtful communication. Journal of Social and Personal Relationships, 21, 291-303. 
Table 1

Frequency of individuals with and without meditation experience by age and by attributional style

\begin{tabular}{|c|c|c|c|c|c|}
\hline & & \multicolumn{3}{|c|}{ AGE } & \multirow[b]{2}{*}{ TOTAL } \\
\hline & & $\begin{array}{l}18-24 \\
\text { years }\end{array}$ & $\begin{array}{l}25-35 \\
\text { years }\end{array}$ & $\begin{array}{l}>35 \\
\text { years }\end{array}$ & \\
\hline With & Count & 28 & 43 & 39 & 111 \\
\hline Meditation & Expected frequency & 41.5 & 40 & 28.5 & \\
\hline Experience & Standardised residuals & -2.1 & .5 & 2.0 & \\
\hline Without & Count & 58 & 40 & 20 & 118 \\
\hline Meditation & Expected frequency & 44.5 & 43 & 30.5 & \\
\hline Experience & Standardised residuals & 2.0 & -.5 & -1.9 & \\
\hline TOTALS* & & 86 & 83 & 59 & 229 \\
\hline
\end{tabular}

\section{ATTRIBUTIONAL STYLE}

DISPOSITIONAL SITUATIONAL TOTAL

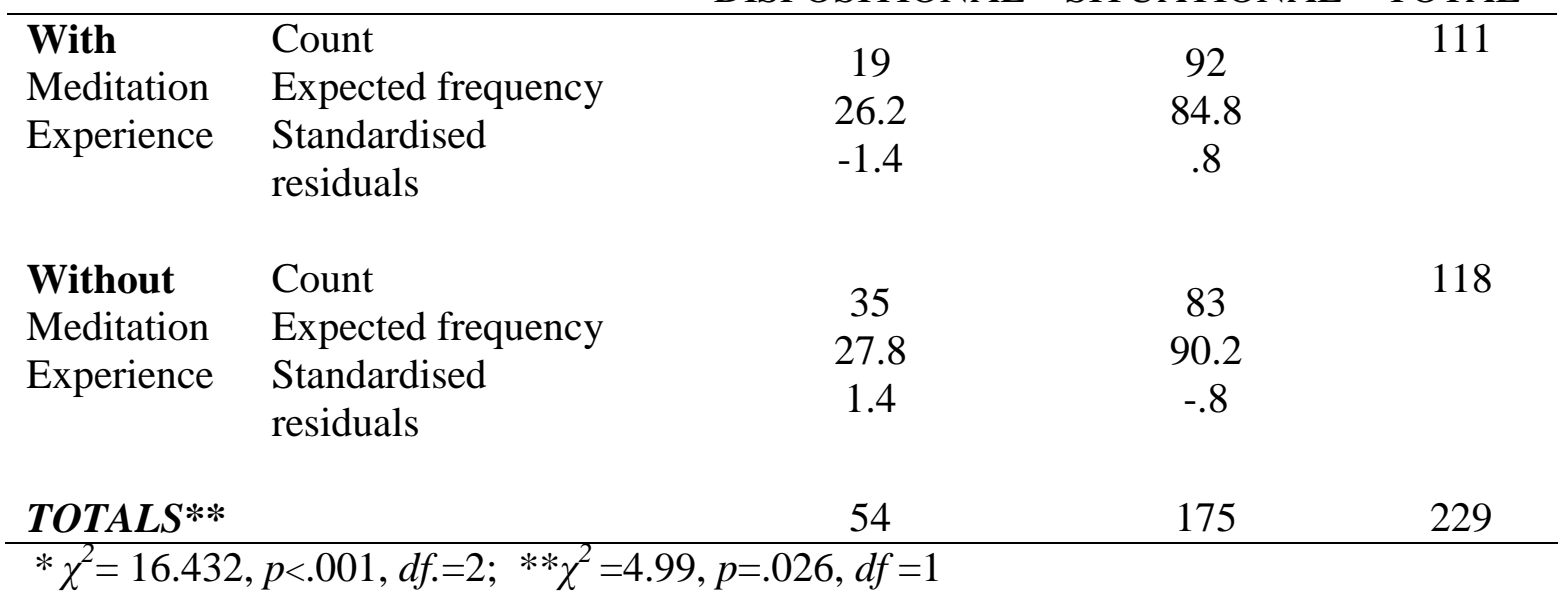


Table 2

Analysis of variance for attributive style and experience with meditation

\begin{tabular}{|c|c|c|c|c|c|c|}
\hline Variables & & $N$ & Mean & $S D$ & $F$ & $d$ \\
\hline $\begin{array}{l}\text { ATTRIBUTIVE } \\
\text { STYLE }\end{array}$ & & & & & & \\
\hline Self-ohservation & Dispositional & 54 & 5.463 & 1.708 & & \\
\hline sent-ouser valion & Situational & 175 & 5.907 & 1.624 & & \\
\hline & All & 229 & 5.802 & 1.651 & 3.012 & .013 \\
\hline & Dispositional & 54 & 2.519 & 2.152 & & \\
\hline Anger & Situational & 175 & 3.480 & 2.456 & & \\
\hline & All & 229 & 3.253 & 2.418 & $6.68 * *$ & .029 \\
\hline & Dispositional & 54 & 3.577 & 1.712 & & \\
\hline Social distance & Situational & 175 & 4.239 & 1.760 & & \\
\hline & All & 229 & 4.083 & 1.767 & $5.91 *$ & .025 \\
\hline EXPERIENCE & & & & & & \\
\hline WITH & & & & & & \\
\hline MEDITATION & & & & & & \\
\hline Self-observation & $\begin{array}{l}\text { Without } \\
\text { experience } \\
\text { With }\end{array}$ & 118 & 5.304 & 1.723 & & \\
\hline & experience & 111 & 6.332 & 1.395 & & \\
\hline & All & 229 & 5.802 & 1.651 & $24.450 * * *$ & .097 \\
\hline Anorr & $\begin{array}{l}\text { Without } \\
\text { experience }\end{array}$ & 111 & 3.688 & 2.324 & & \\
\hline Anger & $\begin{array}{l}\text { With } \\
\text { experience }\end{array}$ & 118 & 2.847 & 2.444 & & \\
\hline & All & 229 & 3.253 & 2.418 & $7.037 * *$ & .030 \\
\hline & $\begin{array}{l}\text { Without } \\
\text { experience }\end{array}$ & 111 & 4.347 & 1.732 & & \\
\hline Social distance & With & & & & & \\
\hline & experience & 118 & 3.835 & 1.772 & & \\
\hline & All & 229 & 4.083 & 1.768 & $4.888^{*}$ & .021 \\
\hline
\end{tabular}

$* \mathrm{p}<.05 * * \mathrm{p}<.01 * * * \mathrm{p}<.001$ 
Table 3

Frequency of individuals with high and low self-observation scores by attributional style in the meditator group

ATTRIBUTIONAL STYLE

DISPOSITIONAL SITUATIONAL TOTAL

\begin{tabular}{lcccc} 
High Self- & Count & 6 & 62 & 68 \\
observation & Expected frequency & 11.6 & 56.4 & \\
& Standardised residuals & -1.7 & .8 & \\
Low Self- & Count & 13 & 30 & 43 \\
observation & Expected frequency & 7.4 & 35.6 & \\
& Standardised residuals & 2.1 & -.9 & \\
TOTALS & & 19 & 92 & 111 \\
\hline
\end{tabular}

$\chi^{2}=8.510, p=.004, d f=1$ 
Table 4

Analysis of variance according to meditation experience and level of self-observation for anger and social distance

\begin{tabular}{lccccc}
\hline Variables & $N$ & Mean & $S D$ & $F$ & $d$ \\
\hline MEDITATORS & & & & &
\end{tabular}

High self-

Anger

observation

Low self-

observation

$\begin{array}{lll}68 & 3.912 & 2.190\end{array}$

$43 \quad 3.323 \quad 2.504$

Total

$\begin{array}{lllll}111 & 3.685 & 2.323 & 1.687 & .015\end{array}$

High self-

$\begin{array}{llll}\text { observation } & 68 & 4.723 & 1.724\end{array}$

Social distance

Low self-

observation

$\begin{array}{lll}43 & 3.753 & 1.589\end{array}$

Total

$\begin{array}{lllll}111 & 4.347 & 1.722 & 8.857 * * & .075\end{array}$

\section{NON-}

MEDITATORS

\begin{tabular}{llllllll}
\multirow{2}{*}{ Anger } & $\begin{array}{l}\text { High self- } \\
\text { observation }\end{array}$ & 43 & 3.465 & 2.729 & & \\
$\begin{array}{l}\text { Low self- } \\
\text { observation }\end{array}$ & 75 & 2.493 & 2.208 & & \\
& Total & 118 & 2.848 & 2.447 & $4.446^{*}$ & .037 \\
& $\begin{array}{l}\text { High self- } \\
\text { observation } \\
\text { Social distance }\end{array}$ & 43 & 4.066 & 1.916 & & \\
& $\begin{array}{l}\text { Low self- } \\
\text { observation }\end{array}$ & 75 & 3.702 & 1.683 & & \\
& Total & 118 & 4.835 & 1.768 & 1.156 & .010 \\
\hline$* \mathrm{p}<.05 ; * * \mathrm{p}<.01$ & & & & & & \\
\hline
\end{tabular}

